\title{
Peran Religiusitas terhadap Quarter-Life Crisis (QLC) pada Mahasiswa
}

\author{
Alfiesyahrianta Habibie ${ }^{1}$, Nandy Agustin Syakarofath ${ }^{2}, \mathcal{E}$ Zainul Anwar $^{3}$ \\ 1,2,3Fakultas Psikologi Universitas Muhammadiyah Malang
}

\begin{abstract}
The purpose of this study was to determine the role of religiosity in the quarter-life crisis in students. The hypothesis proposed was that religiosity plays a role in the quarterlife crisis of students. This research used survey quantitative research methods. Participants in this study were 219 college students (95 males and 124 females) from various study programs in Indonesia aged 18-25 year old. The instruments used were the Abrahamic religiosity scale and the quarter-life crisis scale. Data were analyzed using regression analysis $(p=0.006 ; r=0.034)$. Religiosity was found to predict how the student's facing a period of a quarter-life crisis and full of challenges to face.
\end{abstract}

Keywords: adolescence; adulthood; quarter-life crisis; religiosity

Abstrak. Penelitian ini bertujuan untuk mengetahui peran religiusitas terhadap quarter-life crisis pada mahasiswa. Hipotesis yang diajukan adalah religiusitas berperan terhadap quarter-life crisis mahasiswa. Penelitian ini menggunakan metode penelitian kuantitatif survei. Partisipan pada penelitian ini adalah 219 mahasiswa (95 laki-laki dan 124 perempuan) perguruan tinggi dari berbagai program studi yang ada di Indonesia usia 18-25 tahun. Intsrumen yang digunakan adalah Abrahamic religiosity scale dan Quarter-life crisis scale. Data yang diperoleh kemudian dianalisis menggunakan uji regresi linier sederhana, hasilnya hipotesis diterima $(p=0,006 ; r=0,034)$. Artinya religiusitas berperan secara signifikan terhadap quarter-life crisis pada mahasiswa. Religiusitas dianggap aspek penting yang memengaruhi mahasiswa didalam menghadapi masa-masa seperempat abad yang penuh dengan berbagai tantangan untuk dihadapi.

Kata kunci: masa dewasa; masa remaja; quarter-life crisis; religiusitas

Setiap individu di dunia pasti akan melewati beberapa tahapan perkembangan mulai dari bayi hingga lanjut usia. Baltes, Lindenberger, dan Staudinger (2006) memaparkan bahwa ada empat tahapan perkembangan yang dilalui yaitu anak-anak, remaja, dewasa dan lansia. Berbeda dengan pendapat tersebut, Erikson (1968) memaparkan bahwasanya ada delapan tahapan yang dilalui oleh setiap individu yaitu bayi, balita, kanak-kanak awal, kanak-kanak pertengahan dan akhir, remaja, dewasa a-

${ }^{1}$ Korespondensi mengenai artikel ini dapat dilakukan melalui alfiesyahrianta@gmail.com

2atau nandysyakarofath@umm.ac.id wal, dewasa menengah, dan dewasa akhir. Sejatinya dari pendapat kedua tokoh tersebut secara umum tahapan yang dilalui adalah bayi, kanak-kanak, remaja, dewasa, dan lansia. Masingmasing dari setiap tahapan perkembangan memiliki karakteristik dan tugas yang berbeda-beda (Anshory, Yayuk, \& Worowirastri, 2016).

Melihat adanya perbedaan karakteristik dan tugas perkembangan, salah satu masa yang dianggap penting dan menjadi perhatian banyak kalangan adalah masa peralihan dari remaja ke dewasa. Menurut Papalia dan Feldman (2014) pada masa ini seseorang sudah 
mulai megeksplorasi diri, mulai hidup terpisah dari orang tua dan mandiri, dan mulai mengembangkan sistem atau nilainilai yang sudah terinternalisasi sebelumnya. Masa di mana individu mulai mengeksplorasi diri dan lingkungannya disebut dengan masa emerging adulthood (Wood et al, 2018). Respons individu di dalam menghadapi masa emerging adulthood berbeda-beda. Banyaknya pilihan yang tersaji dari lingkungan eksternalnya dan kebingungan cara menghadapi untuk memutuskan mana yang dirasa sesuai (pilihan yang benar) cenderung membuat stres (Atwood \& Scholtz, 2008). Ada individu yang merasa senang dan antusias dan tertantang untuk menjelajahi kehidupan baru yang belum pernah dirasakan, namun ada juga yang merasakan kecemasan, tertekan dan hampa (Nash \& Murray, 2010).

Individu yang di dalam melewati tahapan perkembangannya tidak mampu merespons dengan baik berbagai persoalan yang dihadapi, diprediksi akan mengalami berbagai masalah psikologis, merasa terombang-ambing dalam ketidakpastian dan mengalami krisis emosional atau yang biasa disebut dengan quarter-life crisis. (Robbins dan Wilner, 2001; Atwood \& Scholtz, 2008). Menurut Fischer (2008) quarter-life crisis adalah perasaan khawatir yang hadir atas ketidakpastian kehidupan mendatang seputar relasi, karier, dan kehidupan sosial yang terjadi sekitar usia 20-an. Mendukung pernyataan tersebur Nash dan Murray (2010) mengatakan bahwa yang dihadapi ketika mengalami quarterlife crisis adalah masalah terkait mimpi dan harapan, tantangan kepentingan akademis, agama dan spiritualitasnya, serta kehidupan pekerjaan dan karier. Permasalahan-permasalahan tersebut muncul ketika individu masuk pada usia 18-28 tahun atau ketika telah menyelesaikan pendidikan menengah, contohnya mahasiswa. Menurut Alifandi (2016) lompatan akademis yang sering dialami oleh mahasiswa ke dunia kerja terkadang menimbulkan luka dan ketidakstabilan emosi sehingga mengalami krisis emosional.

Krisis yang dialami mahasiswa disebabkan oleh berbagai tuntutan kehidupan yang dihadapi. Umumnya penyebab krisis yang utama adalah karena adanya tuntutan dari orang tua terhadap langkah apa yang akan diambil di masa mendatang (Arnett, 2004) dan stres karena masalah akademik (Slamet 2003; Kartika, Deria, \& Ruhansih, 2018). Telah diketahui bersama bahwasanya Indonesia adalah negara kolektivistik di mana penilaian dan tanggapan dari lingkungan adalah hal yang dianggap penting bahkan dapat memengaruhi bagaimana individu berperilaku. Tantangan lain yang turut berkontribusi terhadap krisis emosional yang dialami oleh mahasiswa adalah kompleksnya masa transisi yang penuh dengan ketidakpastian sehingga menimbulkan depresi bagi individu yang mengalami (Haase, Heckhausen, \& Silbereisen, 2012). Hal ini diperparah dengan pengalaman negatif seperti berbagai penolakan yang berdampak langsung terhadap kesejahteraan pribadi, harga diri (Robinson, 2018). Untuk mengatasi kondisi ini banyak sekali faktor yang dapat menjadi filter agar individu lebih kuat menghadapi quarter-life crisis yang dialami sehingga dapat melaluinya dengan baik.

Krisis emosional yang dialami mahasiswa dalam jangka waktu panjang dapat menyebabkan konsekuensi negatif terhadap kehidupan, salah satunya stres bahkan depresi. Kondisi stres yang terakumulasi diprediksi memunculkan berbagai permasalahan baru, yaitu masalah emosi dan perilaku (Jackson \& 
Warren, 2000), perilaku agresi, tindak kekerasan dan respons yang emosional (Veenema et al., 2006), rendahnya kesejahteraan psikologis (ZimmerGembeck, \& Skinner, 2008; Shultz \& Wang, 2011), penarikan diri secara sosial, kecemasan, dan depresi (Attar, Guerra, \& Tolan, 1994) serta trauma (Lazarus \& Folkman, 1984). Kurangnya penghayatan, kepercayaan dan partisipasi aktif pada kegiatan keagamaan yang dianut dapat menyebabkan berbagai persoalan yang telah disebutkan, khususnya depresi dan kehilangan tujuannya. Umumnya penurunan penghayatan terhadap agama yang dianut banyak terjadi pada kalangan muda di usia 18-24 tahun (Bryant, 2010). Kondisi ini identik dengan kehidupan mahasiswa yang juga turut berada pada rentang usia 20-an. Artinya, berdasarkan pemaparan tersebut mahasiswa rentan mengalami berbagai persoalan psikologis yang disebabkan oleh penurunan tingkat penghayatan terhadap agamanya (religiusitas).

Suhardiyanto (2001) mendefinisikan religiusitas sebagai bentuk hubungan pribadi dengan sosok yang diyakini (Tuhan) dengan konsekuensi munculnya hasrat untuk taat dan patuh terhadap apa yang dianjurkan dan yang dilarang-Nya. Mendukung pernyataan tersebut religiusitas dianggap sebagai tingkat pengatahuan, keyakinan, pelaksanaan ibadah dan akidah, serta penghayatan atas agama melalui amal perbuatan (Nashori dan Mucharam, 2002). Koenig dan Larson (2001) berpendapat bahwa kebahagiaan, emosi positif, kepuasan akan kehidupan serta moral yang lebih baik dapat diperoleh dengan meningkatkan keyakinan dan praktik di dalam beragama. Bahkan lebih jauh dampak keyakinan dan praktik keagamaan pada kalangan muda adalah menurunkan gejala depresi dan harga diri yang lebih baik (Yonker, Schnabelrauch, \&
De Haan, 2012; Brantley et al., 2015; Mohamad, Draman, Aris, Musa, \& Rus (2016).

Melihat adanya keterkaitan antara krisis emosional yang sering dihadapi oleh mahasiswa di usia 20-an karena menghadapi quarter-life crisis yang berdampak buruk terhadap kondisi psikologisnya, namun di sisi lain ada efek dari penghayatan terhadap keagaman yang dianut (religiusitas) terhadap krisis emosional yang dihadapi maka penting untuk dikaji lebih dalam keterkaitan langsung antara religiusitas seseorang dengan masa quarter-life crisis yang dihadapi. Tujuannya adalah untuk menyiapkan individu yang sedang mengalami masa quarter-life crisis dapat memahami kondisi yang dihadapi dan mengetahui dengan pasti bagaimana salah satu cara penanganannya. Di samping itu, peneliti berharap hasil dari penelitian ini dapat berkontribusi terhadap literasi mengenai berbagai fenomena keilmuan psikologi khususnya yang berkaitan dengan remaja dan tahap perkembangannya.

\section{Metode}

Subjek yang berpartisipasi di penelitian ini sejumlah 219 mahasiswa berusia 18-25 tahun. Pemilihan partisipan menggunakan random sampling (sampel acak) dengan bantuan random.org dan snowball (pesan berantai).

Terdapat dua variabel dalam penelitian ini, yaitu religiusitas sebagai variabel bebas dan quarter-life crisis sebagai variabel terikat yang kemudian disebarkan secara daring menggunakan Google Form melalui Facebook dan Whatsapp.

Variabel religiusitas diukur menggunakan skala yang dikembangkan oleh Khodayarifard et al. (2018) terdiri dari 35 item dan sudah diterjemahkan ke 
dalam bahasa Indonesia dengan nilai koefisien reliabilitas skala sebesar 0,976. Selanjutnya pada variabel quarter-life crisis menggunakan skala yang disusun oleh Agustin (2012) yang terdiri dari 23 item kemudian diadaptasi oleh peneliti sesuai dengan konteks penelitian yang dilakukan dengan nilai koefisien reliabilitas skala quarter-life crisis 0,924 . Pilihan jawaban dari kedua skala menggunkan skala Likert yang bergerak dari 1 (sangat tidak setuju), 2 (tidak setuju), 3 (setuju), dan 4 (sangat setuju).
Data yang diperoleh kemudian dianalisis menggunakan teknik regresi linier sederhana menggunakan program perhitungan statistika SPSS versi 24 .

\section{Hasil}

Subjek dalam penelitian ini adalah sejumlah 219 mahasiswa yang berusia 1825 tahun. Secara terperinci, data demografi subjek penelitian yang terkumpul dapat dilihat pada Tabel 1.

\section{Tabel 1.}

Deskripsi Subjek Penelitian

\begin{tabular}{crc}
\hline \multicolumn{1}{c}{ Kategori } & Frekuensi & Persentase (\%) \\
\hline Jenis Kelamin & & \\
- Laki-laki & 95 & 43,3 \\
- Perempuan & 124 & 56,6 \\
Usia & & \\
- 18 & 15 & 6,8 \\
- 19 & 42 & 19.2 \\
- 20 & 41 & 18,7 \\
- 21 & 53 & 24,2 \\
- 22 & 45 & 20,5 \\
- 23 & 15 & 6,8 \\
- 24 & 6 & 2,7 \\
- 25 & 2 & 0,9 \\
Agama & & \\
- Islam & 91 & 41,6 \\
- Kristen & 40 & 18,3 \\
- Katolik & 37 & 16,9 \\
- Budha & 46 & 21,0 \\
- Hindu & 5 & 2,3 \\
\hline
\end{tabular}

Berdasarkan data demografi pada Tabel 1 dipaparkan data bahwa sebaran jumlah partisipan lebih besar laki-laki dibandingkan perempuan. Pada laki-laki sejumlah 95 orang $(43,3 \%)$ sedangkan partisipan perempuan sejumlah 124 orang (56,6\%). Adapun rentang usia partisipan yang bersedia terlibat dalam penelitian ini rata-rata berada pada rentang usia 18-25 tahun saat berada pada fase quarter-life crisis sesuai dengan tahapan usia perkembangannya, secara terperinci jumlah partisipan berusia 18 tahun sebanyak 15 orang $(6,8 \%), 19$ tahun sebanyak 42 orang $(19,2 \%), 20$ tahun sebanyak 41 orang $(18,7 \%), 20$ tahun sebanyak 41 orang $(18,7 \%), 21$ tahun sebanyak 53 orang $(24,2 \%), 22$ tahun sebanyak 45 orang $(20,5 \%), 23$ tahun sebanyak 15 orang $(6,8 \%), 24$ tahun 
sebanyak 6 orang $(2,7 \%)$, dan 25 tahun sebanyak 2 orang (0,9\%). Selanjutnya ada lima jenis keyakinan yang dianut oleh partisipan yang terlibat dalam penelitian ini yaitu agama Islam sebanyak 91 orang $(41,6 \%)$, Kristen sebanyak 40 orang $(18,3 \%)$, Katolik sebanyak 37 orang $(16,9 \%)$, Budha sebanyak 46 orang $(21 \%)$, dan Hindu sebanyak 5 orang (2,3\%). Dalam penelitian ini hanya lima jenis agama yang dianut oleh partisipan mengingat di Indonesia hanya kelima keyakinan tersebut yang diakui dan sah di mata undang-undang yang berlaku.

Berdasarkan Tabel 2 hasil uji perbandingan rata-rata quarter-life crisis mahasiswa berdasarkan jenis kelamin adalah, pada mahasisa laki-laki dan sebesar 54,86 dengan $S D=10,976$ sedangkan pada perempuan sebesar 54,63 dengan $S D=10,549$. Selanjutnya hasil uji
Namun demikian, jika dianalisis secara terperinci kontribusi dari religiusitas di dalam menghadapi quarterlife crisis berdasarkan aspeknya didapatkan nilai kontribusi berbeda-beda (lihat Tabel 3).

Angka korelasi religiusitas terhadap masing-masing aspek quarter-life crisis berkontribusi negatif pada aspek kebimbangan dalam mengambil keputusan $(-0,097)$, putus asa $(-0,111)$, penilaian diri negatif $(-0,231)$, terjebak dalam situasi sulit $(-0,066)$, cemas $(-0,097)$, dan tertekan $(-0,023)$. Pada aspek khawatir akan relasi interpersonal, kontribusi religiusitas positif sebesar 0,540. Hasil penelitian ini menunjukkan bahwa tingkat religiusitas yang baik dapat mengurangi kebimbangan yang dirasakan oleh individu ketika akan mengambil sebuah keputusan, rasa putus asa, penilaian diri

Tabel 2.

Mean dan Standar Deviasi Quarter-life Crisis \& Religiusitas Ditinjau dari Jenis Kelamin

\begin{tabular}{llccc}
\hline & Jenis Kelamin & $N$ & Mean & SD \\
\hline \multirow{2}{*}{ Quarter-life crisis } & Laki-laki & 95 & 54,86 & 10,976 \\
& Perempuan & 124 & 54,63 & 10,549 \\
& Laki-laki & 95 & 121,98 & 12,019 \\
& Perempuan & 124 & 123,07 & 11,592 \\
\hline
\end{tabular}

perbandingan rata-rata religiusitasnya jika dilihat dari perbedaan jenis kelamin diperoleh pada mahasiswa laki-laki sebesar 121,98 dengan SD 12,019, dan perempuan sebesar 123,07 dengan SD 11,592 .

Uji analisis menggunakan uji regresi linier dan hasil menunjukkan $(p=0,006$; $r$ $=0,034$ ) bahwasanya hipotesis diterima. Artinya ada pengaruh yang signifikan dari religiusitas terhadap quarter-life crisis pada mahasiswa. Nilai kontribusi pengaruh religiusitas terhadap quarter-life crisis sebesar $3,4 \%$ dan $6,6 \%$ lainnya disumbangkan melalui faktor lain. yang negatif, perasaan bingung ketika terjebak dalam situasi yang dianggap sulit, perasaan cemas, dan tertekan. Namun, pada aspek kekhawatiran seseorang akan relasi interpersonal berbanding terbalik, semakin tinggi tingkat religiusitas yang dimiliki maka semakin besar kekhawatiran yang dirasakan terkait hubungannya dengan sesama manusia.

\section{Diskusi}

Hasil penelitian ini menunjukkan bahwa religiusitas berpengaruh terhadap quarterlife crisis mahasiswa $(p=0,006<0,05)$. 
Kontribusi pengaruh dari religiusitas sebesar 3,4\% dan arahnya negatif. Artinya semakin tinggi tingkat religiusitas individu maka semakin rendah pula tingkat quarter-life crisis-nya begitu sebaliknya, sehingga hipotesis penelitian terbukti. protektif. Sebagai faktor protektif, bahkan religiusitas dianggap berpengaruh terhadap daya kelentingan ketika berada dalam masa-masa yang sulit atau resiliensi individu (Suryaman, Stanislaus, \& Mabrur, 2014).

Jika dilihat secara terperinci pada

Tabel 3.

Hasil Uji Korelasi Religiusitas dengan Aspek Quarter-life Crisis

\begin{tabular}{lc}
\hline \multicolumn{1}{c}{ Uji korelasi religusitas terhadap aspek quarter-life crisis } & $\boldsymbol{r}$ \\
\hline Kebimbangan dalam mengambil keputusan & $-0,097$ \\
Putus Asa & $-0,111$ \\
Penilaian diri negatif & $-0,231$ \\
Terjebak dalam situasi sulit & $-0,097$ \\
Cemas & $-0,066$ \\
Tertekan & $-0,023$ \\
Khawatir akan relasi interpersonal & 0,540 \\
\hline
\end{tabular}

Gambaran pengaruh religiusitas terhadap quarter-life crisis seperti pada situasi ketika seseorang dihadapkan dengan kejadian yang penuh kebimbangan namun ia tetap tahan menghadapi. Mendukung hal tersebut, Hawari (1997) berpendapat bahwa seseorang yang memiliki pedoman hidup dan daya tahan yang baik ketika menghadapi masalah disebabkan karena kokohnya religiusitas yang dimiliki. Individu dengan tingkat religiusitas yang baik, dianggap lebih tangguh dan mapan ketika mengalami kebimbangan atau merasa tertekan atas hal-hal atau kejadian yang tidak dapat dikendalikan (Wen, 2010), mampu mengelola stres dengan baik (Yudra, Fikri \& Hidayat, 2018), dan dapat menurunkan kecemasan (Maisaroh dan Falah, 2011; Shekhar \& Hussain, 2017). Artinya, berdasarkan pemaparan tersebut dapat diasumsikan bahwa religiusitas pada diri individu turut berkontribusi terhadap berbagai kondisi negatif dan permasalahan yang dihadapi, lebih jauh lagi tingkat religiusitas dapat menjadi faktor pemicu dan faktor aspek masing-masing religiusitas dan keterkaitannya dengan quarter-life crisis yang dialami oleh mahasiswa, didapatkan fenomena yang berbeda. Pada aspek kebimbangan dalam mengambil keputusan, putus asa, penilaian diri negatif, perasaan terjebak dalam situasi sulit, perasaan cemas, dan perasaan tertekan, kontribusi religiusitas adalah mengurangi berbagai perasaan negatif yang dirasakan sehingga menjadi lebih adaptif meskipun pengaruhnya tidak begitu kuat. Sedangkan pada aspek kekhawatiran akan relasi interpersonalnya berbanding terbalik. Semakin tinggi tingkat religiusitasnya individu maka kekhawatiran akan relasi interpersonalnya semakin meningkat karena angka korelasinya positif.

Pada dasarnya agama menuntut manusia agar hubungannya tidak hanya dengan Tuhan saja yang baik tetapi juga dengan sesama manusia. Artinya relasi interpersonal dengan individu lainnya sangat dianggap penting. Alasan kenapa kemudian tingkat religiusitas yang tinggi justru semakin membuat seseorang 
khawatir akan relasi interpersonalnya adalah individu yang bersangkutan sedang mempertanyakan apakah caracara yang dilakukan ketika berinteraksi dan berkomunikasi dilakukan dengan cara yang benar atau tidak. Hal ini menimbulkan kekhawatiran sehingga individu yang bersangkutan semakin meningkatkan dan memperbaiki cara-cara yang baik di dalam berinteraksi dengan orang lain. Bahkan cara-cara yang baik didalam berinteraksi dengan orang lain di dalam Islam dianggap tindakan yang terpuji bahkan dianjurkan (Jufri, 2017).

Secara umum dari penelitian yang dilakukan religiusitas memengaruhi quarter-life crisis yaitu sebesar 3,4\% sedangkan sisanya sebesarnya $96,6 \%$ di luar dari religiusitas yang berasal dari faktor internal maupun eksternal. Menurut Thouless (2000) pada faktor internal yang dianggap berkontribusi terhadap quarter-life crisis adalah pengalaman pribadi, moral, faktor emosi dan afeksi, serta faktor kapasitas intelektual, sedangkan pada faktor eksternal adalah kondisi sosial dan lingkungan, tingkat pendidikan, tradisi dan budaya serta tuntutan hidup seharihari.

\section{Kesimpulan}

Religiusitas berperan bagi individu di dalam menghadapi masa quarter-life crisis. Pengaruh religiusitas terhadap quarter-life crisis sebesar 3,4\% sedangkan sisanya sebesarnya $96,6 \%$ di luar dari religiusitas yang berasal dari faktor internal maupun eksternal seperti pengalaman pribadi, moral, faktor emosi dan afeksi, serta faktor kapasitas intelektual, kondisi sosial dan lingkungan, tingkat pendidikan, tradisi dan budaya serta tuntutan hidup sehari-hari.
Saran

Peran religiusitas yang berkontribusi nyata terhadap cara individu menghadapi masa-masa penuh kebimbangan ketika menghadapi quarter-life crisis perlu menjadi pertimbangan bagi berbagai pihak untuk dikaji lebih mendalam. Nilainilai kebaikan di dalam agama dianggap mampu membantu individu menyelesaikan persoalan-persoalan lebih terarah sesuai dengan akar permasalahan yang dihadapi. Salah satu upaya yang bisa dilakukan agar remaja lebih siap dan adaptif di dalam menghadapi masa quarte-life crisis tersebut dengan melibatkan orang tua. Pasalnya orang tua adalah lingkungan terdekat anak yang bertugas dan bertanggung jawab atas fungsi-fungsi psikologis, pendidikan, sosial-ekonomi, dan religiusitas selama anak berada di dalam pengasuhannya.

\section{Kepustakaan}

Alifandi, (2016). Kelelahan emosi (emotional exhaustion) pada mahasiswa yang bekerja paruh waktu (studi pada mahasiswa Universitas Negeri Semarang yang bekerja paruh waktu) (Skripsi tidak dipublikasikan). Semarang: Universitas Negeri Semarang.

Anshory, I., Yayuk, E., \& Worowirastri, D. (2016). Tahapan dan karakteristik perkembangan belajar siswa sekolah dasar (upaya pemaknaan development task). The Progressive and Fun Education Seminar. Diakses melalui https://publikasiilmiah.ums.ac.id/bit stream/handle/11617/7670/45.pdf?se quence $=1 \&$ isAllowed $=y \quad$ (pada 12 Oktober 2019).

Arnett, J. J. (2004). Emerging adulthood: The winding road from the late teens through the twenties. New York, NY, US: Oxford University Press. 
Attar, B. K., Guerra, N. G., \& Tolan, P. H. (1994). Neighborhood disadvantage, stressful life events, and adjustment in urban elementary-school children. Journal of Clinical Child Psychology, 23(4), 391-400. doi: 10.1207/s15374424jccp2304 5

Atwood, J. D., \& Scholtz, C. (2008). The quarter-life time period: An age of indulgence, crisis or both? Contemporary Family Therapy, 30(4), 233-250. doi: 10.1007/s10591-0089066-2

Agustin, I. (2012). Terapi dengan pendekatan solution focused pada individu yang mengalami quarter life crisis (Tesis tidak dipublikasikan). Depok: Universitas Indonesia.

Baltes, P. B., Lindenberger, U., \& Staudinger, U. M. (2006). Life span theory in developmental psychology. In R. M. Lerner \& W. Damon (Eds.), Handbook of child psychology: Theoretical models of human development (pp. 569-664). Hoboken, NJ, US: John Wiley \& Sons Inc.

Brantley, J. G., Ekblad, A. G., Smoski, M. J., Greeson, J. M., Wolever, R. Q., Suarez, E. C., \& Lynch, T. R. (2015). Decreased symptoms of depression after mindfulness-based stress reduction: potential moderating effects of religiosity, spirituality, trait mindfulness, sex, and age. The Journal of Alternative and Complementary Medicine, 21(3), 166174. doi: $\underline{10.1089 / \mathrm{acm} .2014 .0285}$

Bryant, A. N. (2010). Souls in transition: The religious and spiritual lives of emerging adults. Christian Smith with Patricia Snell. Religion $\mathcal{E}$ Education, 37(3), 279-283. doi: $\underline{10.1080 / 15507394.2010 .513948}$

Erikson, E. H. (1968). Identity, youth and crisis. London: Faber and Faber.
Fischer, K. (2008). Ramen noodles, rent and resumes: An after-college guide to life. California: SuperCollege LLC.

Haase, C. M., Heckhausen, J., \& Silbereisen, R. K. (2012). The interplay of occupational motivation and well-being during the transition from university to work. Developmental Psychology, 48(6), 1739-1751. doi: 10.1037/a0026641

Hawari, D. (1997). Alquran dan ilmu jiwa. Yogyakarta: Mizan Press

Jackson, Y., \& Warren, J. S. (2000). Appraisal, social support, and life events: Predicting outcome behavior in school-age children. Child Development, 71(5), 1441-1457. doi; $10.1111 / 1467-8624.00238$

Jufri, N. I. (2017). Pertemanan perspektif Alqur'an (suatu tinjauan metode maud) (Tesis tidak dipublikasikan). Makassar: Universitas Islam Negeri Alauddin.

Kartika, R. D., Deria, D. \& Ruhansih, D. S., (2018). Hubungan antara strategi penanggulangan stres (coping stress) dengan keyakinan diri mampu (SelfEficacy) pada mahasiswa yang sedang menyusun tugas akhir di jurusan radiodiagnostik dan radiotherapy politeknik " $\mathrm{X}$ " Bandung. Fokus, 1(1). 1-10. doi: 10.22460/q.v1i1p11-18.498

Khodayarifard, M., Abdollahi, A., AkbariZardkhaneh, S., Afrooz, G., Rahiminezhad, A., Paknejad, M, Shokohi-Yekta, A., Ghobary, B., Azarbayejani, M., Brinthaupt T., \& Hood, R. W. (2018). Abrahamic religiosity scale: Development and initial validation. Mental Health, Religion \& Culture, 21(9-10), 1-11. doi: $\underline{10.1080 / 13674676.2018 .1434495}$

Koenig, H. G., \& Larson, D. B. (2001). International review of psychiatry religion and mental health: Evidence for an association. International 
Review of Psychiatry, 13, 67-78. doi: 10.1080/09540260124661

Lazarus, R S. \& Folkman, S. (1984). Stress, appraisal, and coping. New York: Springer.

Maisaroh, E. N., \& Falah, F. (2011). Religiusitas dan kecemasan menghadapi ujian nasional (UN) pada siswa madrasah aliyah. Proyeksi, 6(2) 78-88. doi: $\underline{10.30659 / p .6 .2 .78-88}$

Mohamad, A. S., Draman, S., Aris, M. A., Musa, R., \& Rus, R. M. (2016). Depression, anxiety, and stress among adolescents in Kuantan and its association with religiosity- a pilot study. The International Medical Journal of Malaysia, 17(2), 91-96.

Nash, R.J., \& Murray, M.C. (2010). Helping college students find purpose: The campus guide to meaning-making. San Francisco, CA: Jossey-Bass.

Nashori, H. F. \& Mucharam, R. D. (2002). Mengembangkan kreatifitas: Perspektif psikologi Islam. Yogyakarta: Menara Kudus.

Papalia, D. E., \& Feldman, R. D. (2014). Menyelami perkembangan manusia (Edisi kedua). Jakarta: Salemba Humanika

Robbins, A \& Wilner, A. (2001). Quarterlife crisis: The unique challenges of life in your twenties. New York: Penguin Putnam, Inc.

Robinson, O. C. (2018). A Longitudinal mixed-methods case study of quarter-life crisis during the postuniversity transition: Lockedout and locked-in forms in combination. Emerging Adulthood, $7(3), \quad$ 167-179. doi: $\underline{10.1177 / 2167696818764144}$

Shekhar, C., \& Hussain, Z. (2017). A study of religiosity and anxiety among undergraduate students (Kargil). International Journal of Applied Social Science, 4(11-12), 447-452.
Shultz, K.S., \& Wang, M. (2011). Psychological perspectives on the changing nature of retirement. American Psychologist, 66(3), 170-9. doi: $10.1037 / \mathrm{a} 0022411$

Slamet. (2003). Belajar dan faktor-faktor yang memengaruhinya. Jakarta: Rieneka Cipta

Suhardiyanto. (2001). Pendidikan religiusitas. Yogyakarta: Kanisius

Suryaman, M. A., Stanislaus, S., \& Mabrur, M. I. (2014). Pengaruh religiusitas terhadap resiliensi pada pasien rehabilitasi narkoba Yayasan Rumah Damai Semarang. Intuisi: Jurnal Psikologi Ilmiah, 6(1), 35.

Thouless, R. H. (2000). Pengantar psikologi agama (Trans.). Jakarta: PT Raja Grafindo Persada

Veenema, A. H., Blume, A., Niederle, D., Buwalda, B. \&Neumann, I. D. (2006). Effects of early life stress on adult male aggression and hypothalamic vasopressin and serotonin. European Journal of Neuroscience, 24(6), 1711-1720. doi: 10.1111/j.1460-9568.2006.05045.x

Wen, Y. H (2010). Religiosity and death anxiety. The Journal of Human Resource and Adult Learning, 6(2), 3137.

Wood, D., Crapnell T., Lau, L., Bennett, A., Lotstein, D., Ferris, M., \& Kuo, A. (2018). Emerging adulthood as a critical stage in the life course. In: Halfon N., Forrest C., Lerner R., Faustman E. (Eds.), Handbook of Life Course Health Development (pp. 123-143). Springer.

Yudra, F. O., Fikri, \& Hidayat, A. (2018). Hubungan antara religiusitas dengan stres kerja pada anggota Brimob Polda Riau. An-Nafs: Jurnal Fakultas Psikologi, 12(1), 12-21.

Yonker, J. E., Schnabelrauch, C. A., \& De Haan, L. G. (2012). The relationship 
between spirituality and religiosity on psychological outcomes in adolescents and emerging adults: A meta-analytic review. Journal of Adolescence, 35(2), 299-314. doi: 10.1016/j. adolescence.2011.08.010
Zimmer-Gembeck, M. J., \& Skinner, E. A. (2008). Adolescents' coping with stress: Development and diversity. Prevention Researcher, 15, 3-7. 